\title{
A Dialectical Analysis of the Ad Baculum Fallacy
}

\author{
Douglas Walton
}

Centre for Research in Reasoning, Argumentation \& Rhetoric

Department of Philosophy

University of Windsor

Windsor, $O N$

Canada N9B 3P4

dwalton@uwindsor.ca

\begin{abstract}
This paper applies dialectical argumentation structures to the problem of analyzing the ad baculum fallacy. It is shown how it is necessary in order to evaluate a suspected instance of this fallacy to proceed through three levels of analysis: (1) an inferential level, represented by an argument diagram, (2) a speech act level, where conditions for specific types of speech acts are defined and applied, and (3) a dialectical level where the first two levels are linked together and fitted into formal dialogue structures. The paper adds a new type of dialogue called advising dialogue that needs to be applied at the third level.
\end{abstract}

Résumé: Cet article applique les structures d'argumentation dialectique au problème de l'analyse du sophisme ad baculum. Afin d'évaluer un présumé exemple de ce sophisme, on montre qu'il est nécessaire de passer par trois niveaux d'analyse: (1) un niveau d'inférence, représenté par un schéma d'argument, (2) un niveau des actes de langage, où des conditions pour certains types d'actes de langage sont définies et appliquées, et (3) un niveau dialectique où les deux premiers niveaux sont reliés entre eux et intégrés dans des structures formelles de dialogue. Cet article ajoute un nouveau type de dialogue appelé dialogue de conseil qui s'applique au troisième niveau.

Keywords: argument from threat, argument from consequences, advicegiving dialogue, dialectical tier, pretending to advise, informal fallacies, types of dialogue, argumentations schemes.

\section{Introduction}

The objective of this paper is not to give an overall survey of ad baculum arguments. That has already been done in the literature, for example in (Walton, 2000). This literature already abundantly recognizes that not all instances of ad baculum arguments are fallacious. The focus of this paper is on the $a d$ baculum fallacy, and the aim of the paper is to show that it needs to be modeled as a dialectical failure, and thus cannot be explained as a purely inferential failure of some sort. The paper 
presents a ten-step evaluation procedure for evaluating whether a given instance of an ad baculum argument is fallacious or not, and a dialectical theory explaining why such an argument is fallacious, if it is, or why not, if it is not.

The ad baculum fallacy is said by the logic textbooks, such as Copi and Cohen $(1990,105)$ to consist in the "appeal to force to cause the acceptance of some conclusion". The normal way of doing this is to make a threat. Some relatively simple examples of this tactic found in the informal logic textbooks are cases of the use of a direct threat by an arguer. More complex cases involve the use of an indirect threat. For example, Copi and Cohen add that an ad baculum argument can be applied with "considerable subtlety" if the arguer uses a "veiled threat" that makes no explicit or direct threat to intimidate a respondent. The ad baculum argument built on such an indirect threat has tended to be a more difficult kind of case to pin down and evaluate by the traditional methods of logic, which define an argument only as a set of propositions comprising premises and a designated member of the set called the conclusion. But in ad baculum examples, context, suggestion and innuendo or implicature are involved, as shown in this paper. Is there some objective way to use such contextual evidence to furnish an objective method to evaluate ad baculum argument of this kind? This paper provides such a method by showing how the inferential and speech act level of analysis of this fallacy needs to be extended to a dialectical level, the so-called dialectical tier of Johnson (1996).

Section 2 gives a brief review of the relevant literature on the ad baculum fallacy. Section 3 presents a simple example of a direct threat argument from the artificial intelligence literature and a more complex textbook example of an indirect threat, and uses simple argument diagrams to make a first pass at grasping the structure of the arguments. Argumentation schemes are applied in sections 4 and 5 to insert additional implicit premises and conclusions into the arguments to get better analyses of the logical structure of the examples. Section 6 formulates sets of requirements that define three types of speech acts, the speech act of warning, the speech act of advising, and the speech act of making a threat. Section 7 briefly explains the notion of an indirect speech act. Section 8 steps up to the dialectical tier by introducing a new type of dialogue called advising dialogue to the existing classification of types of dialogue that function as frameworks for argumentation. Two examples from Consumer Reports are given to illustrate this type of dialogue and reveal its main characteristics. Section 9 presents a dialectical analysis of the argumentation in both examples. The analysis explains why the argument in each example should be taken to be an instance

(C) Douglas Walton. Informal Logic, Vol. 34. No. 3 (2014), pp. 276-310. 
of the ad baculum fallacy or not. Section 10 explains how the fallacy works in the example by showing the juxtaposition of appearance and reality that is revealed once the dialectical structure of the argumentation in the case has been analyzed. Section 11 summarizes the method of evaluating ad baculum arguments as a ten-step procedure and offers some general conclusions and suggestions for further research.

\section{The literature on ad baculum}

According to the account given in this paper, not all ad baculum arguments are fallacious. The goal of the paper is to diagnose what has gone wrong when such an argument is used fallaciously, and so the brief survey of the literature in this section covers previous attempts to solve this problem. A wider survey on the ad baculum arguments can be found in (Walton 2000).

Woods and Walton (1976) surveyed the accounts of the ad baculum fallacy in the logic textbooks, concluding that these accounts have so far failed to solve the problem of explaining why the ad baculum argument is fallacious. They analyzed the form of the argument as being a disjunctive syllogism of a kind that can be classified as a prudential type of argument. However they added that in many instances such a prudential argument could be seen as reasonable. They concluded that the question is open on how instances of arguments normally classified as ad baculum in the logic textbooks can be diagnosed as fallacious. Woods (1987) reaffirmed the earlier Woods-Walton conclusion that argumentum ad baculum can be a reasonable form of argument because it meets the standards required for prudentially sound argument. An argument from negative consequences can often be a good argument by incorporating a threat to negative consequences, that can often be a reasonable basis for one party to commend a certain line of action to another party.

Opinions in the literature on ad baculum are sharply divided on the issue of whether trying to build a dialectical analysis of the fallacy is a good direction for research. Van de Vate (1975) characterized this type of argument as being inherently dialectical. Van de Vate made this point as follows (1975, 45): "Regarding the appeal clearly as an appeal to force must involve at least two parties. One can't appeal to force to oneself." In order to understand the fallacy, he theorized that one must situate the ad baculum argument in the context of an argumentative exchange between two parties. Wreen (1988)

(C) Douglas Walton. Informal Logic, Vol. 34. No. 3 (2014), pp. 276-310. 
argued that the ad baculum fallacy is not dialectical and is not based on threats. Brinton (1992) argued that the ad baculum fallacy is dialectical and is based on threats. Walton (2000) argued that the ad baculum fallacy is dialectical.

The exchange between Wreen (1988) and Brinton (1992) was particularly significant in suggesting directions that future research on the ad baculum fallacy would take. Wreen offered a number of examples of the ad baculum fallacy, and showed that they centrally involved a particular form of argument in which one party threatens another party by advising the other party that he should carry out a particular action or suffer some negative consequences which the first party will bring about. He offered the following typical example: if you don't give me your money, I will shoot you; getting shot would be a very bad outcome for you; therefore you should give me your money. Wreen saw this inferential structure as an instance of the form of argument known in the literature as practical reasoning. Brinton went on to argue that Wreen's theory was a good starting point, but it failed to take into account other elements that are necessary for an adequate model of the ad baculum argument that can be used to explain how the fallacy works.

Brinton $(1992$, 90) argued that the structure of the ad baculum fallacy involves what he called an agent-patient relationship, a context of use into which the inferential structure of the ad baculum argument is embedded. He argued that successful use of the argumentum ad baculum presupposes a relationship of power between two parties. On this account of this relationship, one party plays the role of an agent while the other plays the role of the patient (Brinton, 1992, 91). In this framework the agent arguer imposes a "presence" on the other party that creates a reason for action within the argument itself. This separation of the inferential and transactional aspects of the argumentum ad baculum turned out to be a prescient indicator of the direction future research on the ad baculum fallacy would take. Brinton's notion of the power relationship between the two parties in an ad baculum argument foreshadowed the status function (see below) used by Budzynska and Witek (2014, section 3.3) to analyze the ad baculum fallacy.

Kielkopf (1980) complained that the textbook treatments of the ad baculum fallacy are superficial and misleading. He cited the treatment of the fallacy in Copi's widely used textbook, saying it is "committed when one appeals to force or the threat of force to cause acceptance of a conclusion." On Kielkopf 's account, $(1980,2)$, this explanation is superficial because it fails to "distinguish between what is relevant as a reason for acting, from what is irrelevant for thinking that a claim is true". This

(C) Douglas Walton. Informal Logic, Vol. 34. No. 3 (2014), pp. 276-310. 
conclusion reinforced the point made by Woods and Walton (1976) and Woods (1987) that appeal to force or the threat of force to cause acceptance of a conclusion, for example in diplomatic negotiations, may not necessarily be fallacious.

In (Walton 2000) a distinction was drawn between three kinds of arguments traditionally classified by the logic textbooks as falling under the heading of ad baculum: (1) the scare tactics type of argument that does not contain a threat, but merely describes some scary outcome to influence a respondent; (2) the threat appeal type of argument, where the making of a threat by one party is used to present an argument designed to try to get another party to take some course of action; and (3) the use of force by one party to try to get the other party to take some course of action. This paper will be exclusively concerned with category (2) and, centrally, with a difficult type of instance of the threat appeal argument where the threat is put forward as an indirect speech act.

The latest development in the analysis of the ad baculum fallacy is a recent paper (Budzynska and Witek, 2014) arguing that it is a deficiency of the standard model (Walton, 2000) that it is merely an inferential model involving premises and conclusions that fails to capture the basic rhetorical technique of this fallacy, which needs to be based on speech acts. Budzynska and Witek (2014, section 3.3) show that the communicative and cognitive tactic deployed in the ad baculum argument is an application of a speech act that has two parts. The directive part of the ad baculum speech act has the use of placing an obligation on the respondent to carry out the action that is the conclusion of the argument. The use of the commissive part of the argument is to indicate the proponent's so-called "status function". The notion of the status function derives from the analysis of speech acts in (Searle, 1969). This function contains the proponent's power to give the respondent binding orders with respect to an action to be carried out. The proponent tells the respondent that he or she should bring about a particular action that is being recommended by the proponent. Using this function, the proponent has the power to make binding directive acts that apply to the respondent in an exchange between the two parties.

\section{Two examples}

We begin with what appears to be a very simple case from artificial intelligence. Kraus, Sycara and Evenchik (1998) have built a computational argumentation model in which agents in a

(C) Douglas Walton. Informal Logic, Vol. 34. No. 3 (2014), pp. 276-310. 
multi-agent system can use argumentation as a mechanism for achieving cooperation and agreement. In their system, agents plan and act together using practical reasoning to resolve conflicts, and one of the ways they resolve conflicts is to negotiate with each other. Quoted below (Kraus, Sycara and Evenchik, 1998) is their leading example used to illustrate in a simple case how two agents might interact in a standard sequence of argumentation.

"For example, imagine two mobile robots on Mars, each built to maximize its own utility. $R_{1}$ requests $R_{2}$ to dig for a certain mineral. $R_{2}$ refuses. $R_{1}$ responds with a threat: "if you do not dig for me, I will break your antenna". $R_{2}$ is faced with the task of evaluating this threat. Several considerations must be taken into account, such as whether or not the threat is bounded, what $R_{1}$ 's credibility is, how important it is for $R_{2}$ to have its antenna intact, so on and so forth. $R_{1}$ may take a different approach if $R_{2}$ refuses to dig, and respond with a promise for a reward: "if you dig for me today, I will help you move your equipment tomorrow". Here, $R_{2}$ needs to evaluate the promise of future reward."

In light of the traditional treatments of the ad baculum fallacy in logic, this example is interesting for several reasons, based on the way the example is presented. The first reason is that even though $R_{1}$ has put forward an argument that takes the form of a threat, it seems to be assumed by the way the example is presented that the argument is not inherently fallacious. When faced with the task of evaluating the threat, $R_{2}$ is said to have several considerations that must be taken into account. These remarks suggest that the threat argument may not be entirely unreasonable, and that it can be responded to appropriately by the asking of critical questions that provide the basis for judging how to respond to the threat.

Also, it is said in the example that each of the robotic agents is built to maximize its own utility. This implies that both robots are programmed with goals, and are autonomous agents that can use practical reasoning to seek actions that are means to carry out these goals. To see how $\mathrm{R}_{2}$ might use this kind of reasoning to figure out what to do, examine the argument diagram in figure 1. In its simplest form, an argument diagram, or argument map as it is often called, is composed of two elements, a set of propositions representing premises or conclusions of arguments, and a set of arrows representing inferences from some propositions to others. For this reason an argument map is often called a box and arrow diagram, a visual representation of an argument formed by drawing arrows leading from text boxes to

(C) Douglas Walton. Informal Logic, Vol. 34. No. 3 (2014), pp. 276-310. 
other text boxes. An argument diagram takes the form of a tree structure in which there is a single proposition representing the ultimate claim or thesis to be proved at the root of the tree. All the other propositions are premises or conclusions that lead along branches of the tree to this root proposition.

An argument diagram can easily be made using pencil and paper, but nowadays there are many argument visualization tools that can be used to assist in drawing an argument diagram that can be saved and later modified. Such argument mapping tools have now become centrally important argumentation methods in their own right, as they can perform different functions that are helpful for clarifying, analyzing, summarizing and evaluating arguments. There are now over sixty computational argument mapping systems (Scheuer et al., 2010) that can be used to summarize or analyze argumentation in a visual format on a computer screen for various purposes. The style of diagrams adopted in this paper is that of the Carneades Argumentation System (CAS). The Carneades editor (version 1.0.2), a visualization tool for CAS, can be accessed at http://carneades.github.com. CAS is an Open Source software (permits users to change it) project, which has the goal of developing tools for supporting a variety of argumentation tasks, including argument mapping and argument evaluation, by applying proof standards and the notion of an audience (Gordon, 2010). Carneades formalizes argument graphs as bipartite directed graphs, consisting of argument nodes linked to statement nodes. In CAS argument maps, statement nodes are represented as text boxes that contain propositions. Argument nodes are represented as circles using a + or - sign inside the circle to denote pro and con arguments.

Carneades treats a convergent argument as two separate arguments by showing the convergent argument as displaying two or more arguments, each indicated by a circle node, each leading separately to the same conclusion. A linked argument is drawn by showing two or more premises leading to the same argument node that then goes by a line with an arrowhead leading to the conclusion. Two linked arguments are shown in figure 1. The statement nodes are the rectangular boxes. The argument nodes are the two circles containing the plus signs. The two premises, in each instance, are the statements in the text boxes to the right of the circle node representing the argument. 


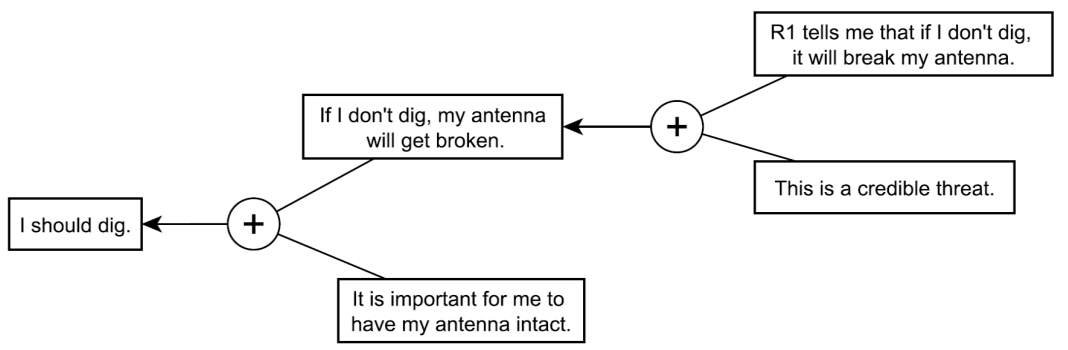

Figure 1: $R_{2}$ 's Reasoning in Response to $R_{1}$ 's Threat.

In figure 1, let's say that an agent's goal is represented by the statement 'It is important for me ....'. Then the argument at the left can be seen as instance of practical reasoning. The argument at the top, let's say, can be represented as an argument from threat. So what's wrong with the threat argument shown in figure 1? Perhaps there is nothing wrong with it, from $R_{2}$ 's point of view. If $R_{2}$ has nothing better to do at that time anyway, but it is important for him to preserve his antenna for future use in the mission, maybe it would make practical sense for it to dig. The upshot of our observations in this example is that it might be very unwise to assume that ad baculum arguments are fallacious, by adopting the theory that making any kind of threat in argumentation should automatically be classified as an unreasonable or fallacious form of argument.

Also, it is said that depending on how $R_{2}$ responds to $R_{1}$ 's argument, $R_{1}$ may take a different approach and put forward a follow-up argument that offers a reward to $R_{2}$. Offering a reward is a typical instance of practical reasoning that proceeds by offering an incentive to the party to whom the argument was directed to try to get the party to carry out a particular action. So if offering a reward is not fallacious, why is it that we seem to jump much more easily to the conclusion that making a threat is generally a fallacious form of argument?

Next let's move on to consider an example that introduces some additional complications. The following case is typical of the kind of example used by the logic textbooks to illustrate cases of an ad baculum fallacy based on a threat (Walton, 2000, 123).

A known gangster says to the owner of a small business: "You should pay us protection money, because this is a very dangerous neighborhood. The last guy who didn't pay had his store looted and destroyed, right after he failed to pay". 
Threats can be nasty, dangerous, impolite, scary, unpleasant, irrelevant, and even illegal in some instances. Hence it is easy to jump to the conclusion that the ad baculum argument used in this case as fallacious. But it is harder to try to pin down a precise general way why an argument of this kind should be evaluated as fallacious. Making a threat is generally recognized as a legitimate tactic in negotiation, thus it is a relevant and important type of argument to be used in strategic maneuvering. For example in contract negotiations between union and management representatives, making a threat is commonly accepted as normal tactic in the strategic maneuvering carried out during the bargaining process by both sides. Of course, the making of a threat can be illegitimate or irrelevant in some instances, but the problem of pinning down exactly what these instances are is not as easy as it looks.

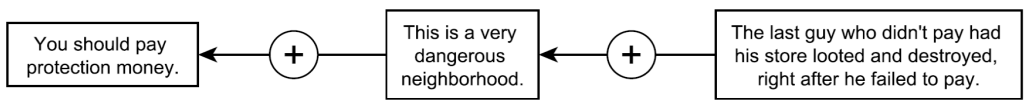

Figure 2: First argument diagram of the gangster example

The argument diagram shown in figure 2 represents the simplest analysis of the argumentation in the gangster example. There are two explicit premises and an explicit conclusion. No indication is given whether either of the arguments fits any known argumentation scheme. This argument diagram seems reasonable enough in representing the basic argumentation structure of the gangster example. The problem is that it is too superficial to reveal anything about the nature of the argument move. It doesn't tell us much of anything, one way or the other, on whether the argument is a fallacious ad baculum or not.

The upshot of our observations on these examples is that it might be very unwise to assume that ad baculum arguments are fallacious, by adopting the theory that making any kind of threat in argumentation should automatically be classified as an unreasonable or fallacious form of argument. To probe into the structure of the argument further we have to use some other tools.

\section{Practical reasoning and argument from consequences}

In the simplest and most basic kind of practical reasoning, a rational agent reasons from a goal, and an action that represents a means to reach the goal, to a conclusion that it should carry out that action. A rational agent is an entity that has goals, some

(C) Douglas Walton. Informal Logic, Vol. 34. No. 3 (2014), pp. 276-310. 
(though normally incomplete) knowledge of its circumstances, the capability of acting to alter these circumstances, and the capability to perceive (some of) the consequences of so acting. It also has the capability for feedback, meaning that it can change its conclusion on how to act and its goals as it gathers incoming knowledge about the consequences of its actions. The following scheme represents the basic form of practical reasoning. In this scheme the first-person pronoun 'I' stands for a rational agent of this kind (Walton, 1996).

Goal Premise: I have a goal, $G$.

Means Premise: Carrying out this action $A$ is a means to realize $G$.

Conclusion: I ought (practically speaking) to carry out this action $A$.

Here the term 'ought' (or equivalently we could use the term 'should') is interpreted as offering prudential reasoning for the wisdom of carrying out a designated action. Practical reasoning is a defeasible form of argumentation, meaning that its conclusion is subject to retraction when new information comes in, even though the original premises of the argument still hold. It can be defeated by the asking of critical questions or by the posing of relevant counterarguments. One of these critical questions concerns negative consequences, often called side effects, of carrying out the action in the conclusion. Practical reasoning can also be attacked by a counterargument that cites negative consequences of the action being contemplated by the practical reasoner, and argues that the negative value of these consequences outweighs the positive value of the goal the agent is trying to fulfill. There are two basic kinds of practical reasoning: instrumental practical reasoning and value-based practical reasoning. The former kind of practical reasoning is not concerned with values, but only with instrumental matters of maximizing utility.

Practical reasoning was involved in the robots example. $R_{2}$ had to decide whether its best course of action was to follow $R_{1}$ 's request to dig, or whether it should risk having this antenna broken by $R_{1}$. To make this decision $R_{2}$ has to weigh whatever goals it might have that might be interfered with by spending time digging against the negative consequences of having its antenna broken, an outcome that might interfere with the goal of the mission. This kind of problem is typical of practical reasoning, where an action being contemplated by an agent might fulfill one goal but have negative consequences with respect to fulfilling another goal.

(C) Douglas Walton. Informal Logic, Vol. 34. No. 3 (2014), pp. 276-310. 
The argument in the gangster example is an instance of the argumentation scheme for argument from negative consequences. The connection between the ad baculum fallacy and argument from negative consequences has been noted by Tindale $(2007,109)$. The argumentation scheme for argument from negative consequences (NC)is presented below.

Major Premise: If $A$ is not brought about, then consequences $C$ will occur.

Minor Premise: Consequences $C$ are bad.

Conclusion: Therefore $A$ should be brought about.

In the gangster example, the gangster is telling the small business owner that if he doesn't pay the protection money, his store will be looted and destroyed. This proposition fits the major premise of the argument from negative consequences. Both parties in the example accept the proposition that the consequences of having his store looted and destroyed are negative from the point of view of the small business owner. The conclusion follows, according to this scheme, that the small business owner should pay protection money.

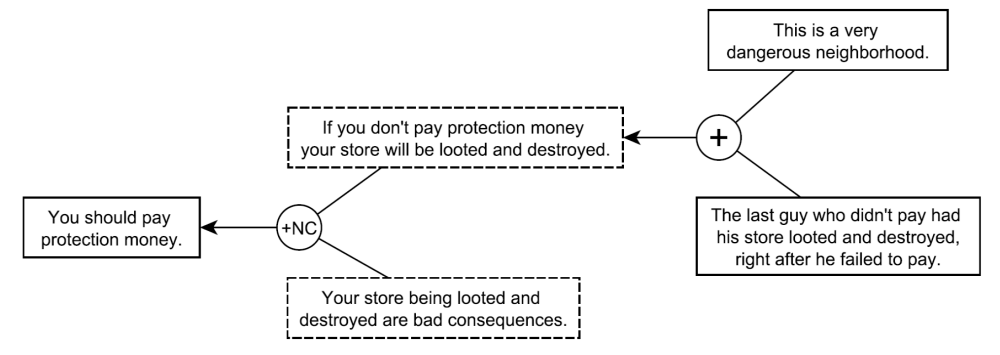

Figure 3: Argument from consequences in the gangster example

Arguments fitting this scheme are known to be fallacious in some instances, but in the broad majority of cases they are very commonly used as reasonable arguments. One needs only to think of a typical example such as, "You ought not to take this drug, because it is known to have the following side effects, one of which in particular is very dangerous for you." This type of example, which cites the negative consequences of the contemplated course of action as a reason for not undertaking an action, is an extremely common form of argument in everyday conversational argumentation, and is often quite reasonable.

This way of reconstructing the argument is somewhat more helpful than the simple way represented in figure 3 . However, it still doesn't tell us much that is very useful in arriving at a

(C) Douglas Walton. Informal Logic, Vol. 34. No. 3 (2014), pp. 276-310. 
solution to the problem of whether the argumentation in the case constitutes a fallacious ad baculum or not. Since arguments from consequences are basically reasonable, or at least do not commit the ad baculum fallacy in their predominant uses, we still don't have much to go on by way of using this structure to devise criteria that will enable us to determine in a particular case whether an argument using a threat is fallacious or not. To get a bit further with this task, it is necessary to probe more deeply into the argument structure of the example.

\section{Argument from threat}

The next tool we need, in addition to the definition of the speech act of making a threat, is the argumentation scheme for argument from threat (Walton Reed and Macagno, 2008, 333). The scheme is presented here in slightly modified form with three premises. The speaker is an agent represented by the firstperson pronoun ' $\mathrm{I}$ '. The hearer is another agent, represented by the pronoun 'you'.

Premise 1: If you do not bring about $A$, some cited bad consequences, $B$, will follow.

Premise 2: I am in position to bring about $B$.

Premise 3: I hereby assert that I will see to it that $B$ occurs if you do not bring about $A$.

Conclusion: You had better bring about $A$.

This argument is precisely the one used in the robots example. Both premises 1 and 3 are explicit in the example, and it may be presumed from the circumstances described in the case that premise 2 also applies. But more work is required to see how it fits to the gangster example.

Figure 4 represents a fuller analysis of how the argumentation in the gangster example contains the making of a threat by inserting five implicit premises.

An explicit premise is shown in a text box that has the form of a normal rectangle. An implicit premise is shown in a text box that is rectangular but where the perimeter of the rectangle is a dashed (dotted) line. The notation + AT in an argument node represents a pro argument from threat. The reader should check to see that the three premises in this argument fit the format required by the scheme for argument from threat above. The notation $+\mathrm{AN}$ in an argument node represents the scheme for argument from analogy. The other two argument nodes are not associated with any specific argumentation scheme, and are

(C) Douglas Walton. Informal Logic, Vol. 34. No. 3 (2014), pp. 276-310. 
merely represented as pro-arguments, as indicated by the plus sign.

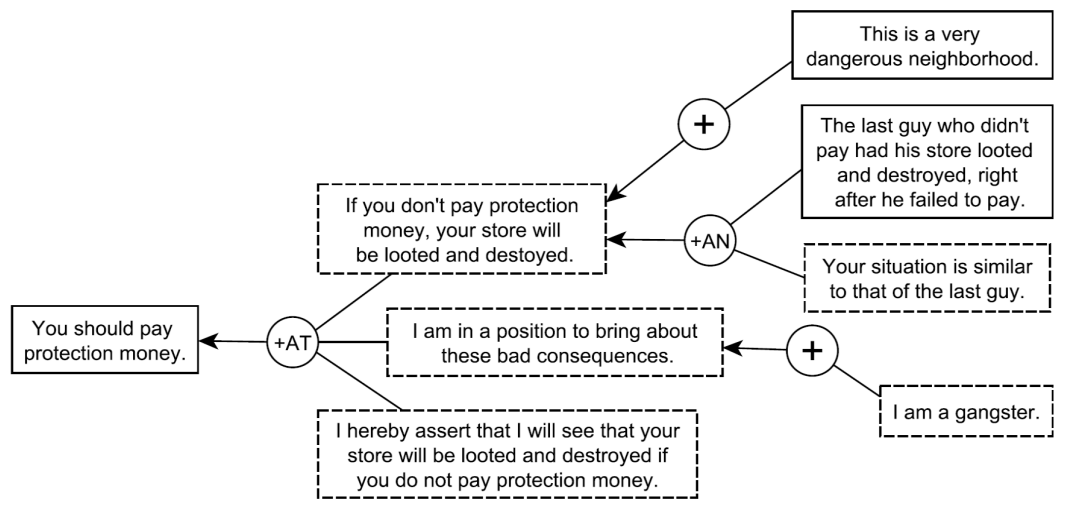

Figure 4: Complex argument diagram of the gangster example with implicit premises

Notice that all three premises in the argument from threat shown in figure 4 are marked as implicit premises. None of them is explicitly stated in the text of the gangster example. This observation by itself should suggest that there is something unusual about the example. Clearly the gangster is making a threat to the store owner, but he has not explicitly stated any of the premises in the argument from threat. When we try to represent the argument diagrammatically to reveal a little more structure, we need to figure out where the two explicitly stated premises should be fitted in. In figure 4 they are shown at the top right. One is the statement that the last guy who didn't pay had his store looted and destroyed, right after he failed to pay. This premise is joined together with an implicit premise stating a similarity to the present case. These two premises are taken to be parts of an argument from analogy, indicated by the AN in the argument circle. It is taken to be a pro-argument supporting the implicit conclusion saying that if the store owner doesn't pay protection money, his store will be looted and destroyed.

The next question about this figure is whether there is any evidence either explicitly or implicitly present in the case that supports the implicit premise that the gangster is in a position to bring about the bad consequences of the store being looted and destroyed. There is implicit evidence, because the store owner is aware that the person he is talking to is a gangster. It can be assumed that he knows about gangsters, and that gangsters are quite capable of bringing about death and destruction in order to achieve their ends. To indicate this implicit evidence on the 
argument diagram in figure 4, an implicit premise containing the statement 'I am a gangster' has been shown as part of a pro argument supporting the conclusion that the speaker is in a position to bring about the bad consequences. Once again here we see that this part of the argument is purely implicit. None of it has been explicitly stated by the gangster.

Now we come to the final point to be discussed. There is one explicit premise of the argument remaining to be dealt with, the statement that this is a very dangerous neighborhood. The problem is how to fit this premise into the argument diagram somewhere. The initial attempt to do that is shown in figure 4, where this statement is represented as a premise in an argument supporting the implicit conclusion that if you don't pay protection money, your store will be looted and destroyed. Viewed in this way the statement is taken to go along with the explicit premise just below it as an additional argument supporting this conclusion. The statement 'This is a very dangerous neighborhood' gives the store owner some reason to accept the proposition that if he doesn't pay protection money, his store will be looted and destroyed.

Notice, however, that this way of representing this part of the argument does not seem quite right. If the store owner already knows that the person confronting him is a gangster, and knows that this man has just stated that the last guy who didn't pay had his store looted and destroyed, right after he failed to pay, he already knows that the gangster is convincingly telling him that if he doesn't pay protection money, his store will be looted and destroyed. The additional statement that this is a very dangerous neighborhood adds nothing in the way of significant evidential support. Something else is going on. The question is: can we get at what else is going on by building a deeper analysis of the argumentation in the case that goes beyond the inadequate argument structures displayed in figures 2,3 and 4 ?

To answer this question it is necessary to examine the function of the statement 'This is a very dangerous neighborhood' in the gangster's argumentation strategy. It appears that the gangster is trying to create a superficial appearance of giving the store owner advice, by warning him of some bad thing that might happen or advising him on how to avoid it, while in reality he is making a nasty threat. To explore the basis of this distinction we have to go to the next level, which goes beyond logic (narrowly construed) to speech act theory. 


\section{Speech acts}

Budzynska and Witek (2014) have shown that speech acts are vitally important for analyzing the ad baculum fallacy, and that it is necessary to bring speech acts to bear on this fallacy to explain its dynamics. The next part of this paper will provide additional evidence to support their approach by demonstrating the importance of speech acts for the analysis of both reasonable and fallacious arguments based on threats.

A speech act is conventionally made up of four components (Searle, 1969):

(1) the two parties involved, called the speaker and hearer,

(2) the propositional content of what was said by the speaker,

(3) the illocutionary act, the intended meaning of the speaker's utterance, and

(4) the perlocutionary act, the action resulting from the locution. There is the possibility of ambiguity in this framework, in that the speech act intended by the speaker can be construed in more than one way. For example, in the gangster case, what he says could be taken as a warning or a threat, even though the evidence that was meant as a threat is quite convincing.

The speech act of warning has the following four conditions (Searle, 1969, 67). The version presented below has been modified from Searle's original account to fit in with subsequent developments in argumentation theory.

Propositional Content Condition: The propositional content of the speech act poses some future event that may affect the hearer.

Preparatory Condition: The speaker has reason to believe that this event will be against the interests of the hearer.

Sincerity Condition: The speaker believes that the hearer will benefit from knowing in advance that this event may occur.

Essential Condition: the action of telling the hearer about the event is taken to offer to the hearer a way of avoiding its coming about or affecting him.

The propositional content condition postulates some event that might come about and affect the interests of the hearer. The preparatory condition requires that the coming about of this event will be against the interests of the hearer. The sincerity condition requires that it is in the hearer's interest from learning about the event before it happens. The essential condition is that there is something the hearer can do about it.

(C) Douglas Walton. Informal Logic, Vol. 34. No. 3 (2014), pp. 276-310. 
Another type of speech act is the speech act of advising (Searle, 1969, 67).

Propositional Content Condition: The propositional content of the speech act describes some future problem or choice the hearer is confronting.

Preparatory Condition: The speaker has reason to believe that choosing one way or another can affect the interests of the hearer.

Sincerity Condition: The speaker believes that the hearer will benefit from knowing in advance about means to solve the problem or make the best choice.

Essential Condition: The action of telling the hearer how to proceed is taken to offer to the hearer a way to solve the problem or make the best choice.

By comparing the two sets of requirements it can be seen how the speech act of warning is different from the speech act of advising. Kauffeld (2000) has offered an analysis of the speech act of advising by contrasting it with the speech act of putting forward a proposal. On his analysis, performing the speech act of proposing carries with it a burden of proof to defend the proposal if challenged to do so, whereas performing the speech act of advising carries no such burden.

According to the analysis of the speech act of making a threat given in (Walton, 2000, 127), the speech acts of giving a warning and making a threat are closely connected. What is important in this analysis is not only the verbal formulae used to make the threat, but attention has to be paid to pragmatic features of the context of dialogue in which the speech act has been put forward as a locution. As noted above, the hearer needs to draw the conclusion that the arguer is making a threat by implicature from the conversational maxims appropriate for the context of dialogue. According to the definition of the speech act of making a threat given in (Walton 2000, 113) there are four speech act conditions that have to be met.

Propositional Content Condition: The hearer has to have reasons to believe that the speaker can bring about the negative consequences in question.

Preparatory Condition: It is presumed by both the speaker and hearer that the negative consequences will not occur without the intervention of the speaker.

Sincerity Condition: The negative consequences will not be in the hearer's interests and the hearer would want to avoid them if possible.

(C) Douglas Walton. Informal Logic, Vol. 34. No. 3 (2014), pp. 276-310. 
Essential Condition: The speaker is making a commitment to see to it that the bad consequences occur unless the hearer carries out the action recommended by the speaker.

The essential difference between the speech act of giving a warning and the speech act of making a threat is the existence of the essential condition. This requirement is characteristic of the speech act of making a threat, and is characteristically absent when the speech act of giving a warning is made. Unless the essential condition is present in a given case, the speech act needs to be classified as a warning, and not a threat.

Is what the gangster said a warning or a threat? And how can it be proved that it fits into one category or the other? It seems that the significant feature of the case, from the point of view of the ad baculum fallacy, is that on the surface, what the gangster said appears to have the form of a warning. But what makes it inviting to classify the example as an instance of the $\mathrm{ad}$ baculum fallacy is that the text can also obviously be taken as expressing a threat - a threat that would be very scary to the store owner - and also might be highly effective in encouraging him to pay the protection money. To find an argumentation method that can be used to capture this ambiguity of expression, and utilize it in an objective way to gather evidence to evaluate whether the argument is fallacious or not, we need to go beyond the inferential structures represented in the three argument diagrams above. We need to consider the context of discourse. To do this it is necessary to make the ascent to a third level, the dialectical level.

\section{Indirect speech acts}

The standard example given to illustrate an indirect speech act is the question, 'Can you pass the salt?' In normal conversational practice this question is not given the literal interpretation, asking the respondent whether she is in a position to pass the salt. It is a polite request to pass the salt by avoiding the somewhat impolite locution 'Pass the salt!' which might appear to be giving a direct order. Indirect speech acts are often used to reject proposals. Consider the following dialogue exchange.

Bob: Would you like to go for a walk?

Alice: I have a doctor's appointment. 
Alice's statement that she has a doctor's appointment does not logically imply rejection of Bob's proposal that they should go for a walk. Hence it is classified as an indirect speech act. But how do we get by inference from Alice's statement that she has a doctor's appointment to the conclusion that she is rejecting Bob's proposal that they should go for a walk? We could insert the missing premise that since Alice has a doctor's appointment this leaves no time for her to go for a walk. But this explanation by itself does not seem very satisfactory.

According to Searle's theory of indirect speech acts, the speaker communicates more than what is explicitly said by relying on common knowledge shared by the speaker and hearer, along with powers of rationality and inference that the speaker presumes that the hearer shares (Searle, 1969). According to Searle's program to build a theory that might help to explain indirect speech acts, the suggestion is made to think of a conversation as an exchange between participants that assumes cooperation and relevance on the part of the participants (Levinson, 1983). This theory needs to assume some more generalized framework of a systematic conversation between parties that follows rules of some sort. The Gricean theory of conversational implicature explains indirect speech acts by framing them in conversational postulates that Grice called maxims (Grice, 1975). Grice offers conversational rules, but does not specify how these rules differ in different kinds of conversational interactions. Nor does he provide a structure that postulates the purpose of a particular type of dialogue, and the kinds of speech acts that function as moves in the dialogue. Nor does he give any indication of systematic criteria enabling a party outside the dialogue to determine whether the dialogue has been successful or not.

Since the advent of argumentation theory, these conversational maxims are associated with rules of dialogue, making up a system of rules called protocols in the artificial intelligence literature. Each speech act in the dialogue has protocols that impose conditions on the putting forward of the speech act by one party at any particular point in the dialogue, and protocols that impose conditions on the range of responses that the other party is allowed to make. Many formal and computational dialogue systems have now also been built in the artificial intelligence literature to represent standard types of communication frameworks (McBurney and Parsons, 2002). Formal systems of persuasion dialogue, information seeking dialogue, inquiry dialogue, deliberation dialogue and negotiation dialogue are now available. Reed (2011) has presented a formal and computational model of argumentation in which speech acts

(C) Douglas Walton. Informal Logic, Vol. 34. No. 3 (2014), pp. 276-310. 
function as the glue between utterances that form a dialogue structure. In these formal systems the speech acts are the locutions (such as making an assertion) that can be made at each move of a dialogue.

To deal with the ad baculum fallacy apparently committed in the gangster example, it is necessary to identify some features illustrated by the argumentation in this example. We know that the gangster is making a threat to the store owner, but at the same time what he purports to be doing is merely advising the store owner on how to avoid danger. We hypothesize that the gangster is arguing in this way in order to avoid the responsibility for having made a threat. His modus operandi for implementing a strategic maneuver to this end is to mask his conversation as an instance of innocent advice-giving. What is invoked is pretense of a framework of advising to mask the inappropriateness of making a threat. To model this strategic maneuver, merely thinking of advising as a type of speech act is too narrow. It is much more advantageous to think of advising as a type of dialogue in its own right. But to my knowledge, advising has not been previously defined as normative type of dialogue in its own right in the argumentation literature. Some work needs to be done to specify the characteristics of this type of dialogue.

\section{Advising dialogue}

In the simplest case, advising dialogue has two parties. In formal dialogue models, one party is usually called the proponent and the other the respondent. We will call the proponent the advisor and the respondent the advice receiver. The proponent's goal is to offer advice to the respondent, and the respondent's goal is to benefit from this advice. The respondent needs to consider the advice, and ultimately to accept or reject it. In a normative model of dialogue, the respondent should only accept the advice if it is good advice. The purpose of the dialogue as a whole is to help the proponent with his attempt to make a decision on what to do in a situation that requires choice, on the problem he confronts. Hence advising dialogue is typically embedded in a larger structure of deliberation dialogue where a single agent or group of agents is trying to solve a problem or decide what to do in circumstances requiring a choice of actions.

Advising dialogue is similar to persuasion dialogue in some respects, but it is not the same thing. In persuasion dialogue, there is a difference of opinions that needs to be resolved. The one party accepts that a certain proposition is true, while the

(C) Douglas Walton. Informal Logic, Vol. 34. No. 3 (2014), pp. 276-310. 
other party is of the opinion that this proposition is false, or at least has doubts that it can be proved to be true. In advising dialogue, one party confronts a problem or choice of actions and relies on the other party to furnish relevant information as an aid in making a good decision based on adequate evidence. Advising dialogue definitely fits the form of argumentation, because the advice given takes the form of pro and contra arguments, arguments that support or attack the recommendation given by the advisor, displaying the evidence on both sides of the decision for the receiver to consider.

An example displaying this feature of advice-giving is the evaluation of the Chrysler 200 family sedan given in (Consumer Reports (Canada), April 2013, 47).

"The 200 is an outdated design that is uncompetitive among family sedans. On the plus side, the ride is compliant and the optional V6 is strong and smooth. The noisy and unrefined four-cylinder gets only 21 miles per gallon overall, the same as the 283-hp V6. The six-speed automatic doesn't shift particularly smoothly or quickly. Though the soft suspension provides decent isolation, it also allows frequent body motions, and handling lacks agility. Most controls are straightforward. Reliability has dropped to below average."

The practice of Consumer Reports is to indicate along with the evaluation whether the car being described fits into their recommended category or not. In the case of this evaluation, there was no checkmark given indicating that this car is recommended. This notation essentially means that the car is not being recommended. Consumer Reports specifies criteria for being recommended, including such matters as whether the vehicle passed safety tests, whether it has proved to be reliable, how high the costs of repair have been, and so forth.

In this case we can clearly see that argumentation is involved. The pro arguments are listed along with the con arguments so that the reader can make an informed decision. In table 1 the set of arguments is classified into pro and con. There are four pro arguments and eight con arguments.

\begin{tabular}{|l|l|}
\hline PRO & CON \\
\hline The ride is compliant. & The 200 is an outdated design \\
\hline $\begin{array}{l}\text { The optional V6 is strong and } \\
\text { smooth. }\end{array}$ & $\begin{array}{l}\text { The } 200 \text { is uncompetitive } \\
\text { among family sedans. }\end{array}$ \\
\hline $\begin{array}{l}\text { The soft suspension provides } \\
\text { decent isolation. }\end{array}$ & The four-cylinder is noisy. \\
\hline
\end{tabular}

(C) Douglas Walton. Informal Logic, Vol. 34. No. 3 (2014), pp. 276-310. 


\begin{tabular}{|l|l|}
\hline $\begin{array}{l}\text { Most controls are } \\
\text { straightforward. }\end{array}$ & The four-cylinder is unrefined. \\
\hline & $\begin{array}{l}\text { The four-cylinder gets only } 21 \\
\text { miles per gallon. }\end{array}$ \\
\hline & $\begin{array}{l}\text { The suspension allows } \\
\text { frequent body motions. }\end{array}$ \\
\hline & Handling lacks agility. \\
\hline & $\begin{array}{l}\text { Reliability has dropped to } \\
\text { below average. }\end{array}$ \\
\hline
\end{tabular}

Table 1: Argument pro and con for the Chrysler 200

It is not just the number of the arguments, however, that is significant. What is significant is that the information about the car's property and performance, based on testing it, is made available to the consumer who is considering buying a vehicle. We can look over the pro and con arguments and decide which ones are more important or less important for arriving at a decision. We can weigh them in with other considerations that are important for her. For example, she might have test-driven this car or others, and she might have special requirements, depending on the uses she has for the car, or she may want special features that are really important to her such as all-wheel drive. Price will also be a factor for most buyers. Also significant in the advice given is the decision of Consumer Reports not to put the Chrysler 200 in the recommended category. For example, some buyers might only consider vehicles in the 'recommended' category.

To deal with this kind of case more effectively, merely thinking of advising as a type of speech act is too narrow. An alternative would be to think of advising as representing a continuous type of discourse containing argumentation. In the argumentation literature, seven basic types of dialogue are recognized: persuasion dialogue, deliberation dialogue, inquiry dialogue, information-seeking dialogue, discovery dialogue, negotiation dialogue, and eristic dialogue. It may be useful to see advising dialogue as a distinctive type of dialogue in its own right that is often embedded within these other types of dialogue. It is especially characteristic that there is an embedding of advising dialogue into deliberation dialogue. When an agent is deliberating on how to solve a problem or what course of action to choose, it may be useful for her to consult with another party who is not a participant in the deliberation dialogue for advice on how to make the best choice. 
This kind of situation is very common when experts are consulted for example.

An example of this type of advising dialogue can be found in an article meant to help someone shopping for a new car to select an in-car electronics system (Connect with Your Car: How to Plug-in Your Music, Apps, and Lifestyle, Consumer Reports, April 2013, 18-20, no author given). In the quoted segment below the author offers some advice to help the reader check for some features worth considering.

"When comparing cars, check that the location of the inputs works for you. They're typically found in the dash, center console, or glove box. The latter two let you keep your device out of sight but may not work as well if you mount your phone in a windshield or dash mount for navigation or handsfree phone calls."

When you buy a new car you will see that the inputs for your electronic devices may be found in one of three places, the dash, the center console, or the glove box. But the author of the article offers practical advice. If the inputs are located in the center console or the glove box, the good consequence of this location is that they will be out of sight. However the bad consequence is also noted that they may not work as well for navigation or hands-free phone calls in this enclosed location. This bit of practical reasoning can be passed on to the reader because the testers of these cars encountered this practical problem when they used the electronic in-car technology themselves. Not just this particular example, but much of the writing in Consumer Reports, can nicely be classified as representing advising dialogue.

Advising dialogue has, in the simplest case, two participants, the advisor and the advice seeker. In the opening stage, the advice seeker poses a problem and asks for help in solving it. The question is more than merely a request for information. It may involve the giving of information, but it is more of a practical request for help on how to proceed in a situation where the advice seeker needs help and the advisor is in a position to provide that help. In advising dialogue, the advice seeker opens the dialogue by posing a problem and explaining to the advisor how he is trying to solve this problem. The advice seeker formulates the problem using the argumentation scheme for practical reasoning. For example, he might tell the advisor that he has a goal that he wishes to carry out, and the problem is that he cannot find the best means to carry out the goal. Therefore he wishes to consult the advisor to 
see if she can suggest a way to resolve this problem. These transactions between the two parties occur during the opening stage.

During the argumentation stage-which will generally contain arguments, presenting information, explanations, warnings, and other speech acts - the advisor continuously provides the kind of help requested. During this stage the advice seeker ask questions about things he does not understand, or other questions relating to the practical reasoning given in the advice. During the argumentation stage the advisor offers advice and the advice seeker asks for explanations and further information about the advice offered so that he can fully understand the means he needs to take in order to solve the problem. As part of the argumentation stage the advice seeker may criticize the plan of action proposed by the advisor, by indicating parts in the plan that he thinks might not work or that appear to be questionable. A plan of action is a sequence of actions and events (Russell and Norvig, 1995, 56) linking goals to actions that are means to achieve the goal or contribute to achieving it.

Once the advice given is sufficient to solve the problem expressed at the opening stage, or otherwise if the discussion has reached the point where no further help can be given, the dialogue reaches its closing stage. The closing stage is reached either if the advisor is satisfied that the advice given to him has been shown to him to be the best way to solve this problem, or if the advisor has tried her best to answer all the questions of the advice seeker, but he is still not convinced that the plan she has recommended is the best means to carry out the goal that he wishes to achieve. In that sense the advice seeking dialogue has not been successful in presenting the advice seeker with a solution to this problem. But it could still be successful in another way if it presented enough information about alternative means of working toward solving the problem so that it helped the advice seeker to move forward by seeking further advice from other sources. Indeed it may well be that the advice seeker has to discuss this problem with a number of advisors so that he can compare their recommendations on the best course of action, evaluate their advice, and either pick out the best action plan or combine the action plans to build a better one that might fulfill the goal the advice seeker wants to achieve. 


\section{Dialectical analysis of the ad baculum arguments in the examples}

An interesting aspect of the robots case as presented is that negotiation is involved in the model of argumentation, suggesting the scenario that in multi-agent reasoning if two agents are deliberating on what to do in a given case, it might be quite reasonable for one of them to try to negotiate with the other in order to move their joint deliberations forward. Parsons and Jennings $(1997,267)$ offered the classic case of two agents engaged in a deliberation dialogue on how to hang a picture. Using practical reasoning they come to the conclusion they need a hammer, and a nail. Their joint goal is to hang the picture and they agree that a means of hanging the picture is to use a nail. They also know that they need a hammer to put the nail in the wall in order to hang the picture. Let's say also that one knows where a hammer can be located while the other knows where to get a nail. Following the example further, let's suppose that they start to negotiate on who will provide the hammer and who will provide the nail. Notice what has happened. They started out engaging in a deliberation dialogue on how to hang the picture, but then at some point the discussion shifted to a negotiation dialogue.

Also it might appear to be a reasonable hypothesis that whether the making of a threat in an argument should be evaluated as a fallacious ad baculum or not depends on the framework of multi-agent dialogue that the argument is supposed to be part of. In the robots example, each of the two robots is built to maximize its own utility, but they need to communicate in order to pass along information about the circumstances to each other in order to carry out the tasks required by each to fulfill the mission. When the one threatens the other, presumably they are engaged in a deliberation dialogue using practical reasoning to carry out their individual goals, and the goal of the mission generally. If there is some problem about which one should carry out a particular task needed to move towards these goals, they may need to negotiate. If a shift of this sort occurs, and during the negotiation interval one makes a threat to the other by using ad baculum argument, this argument is not necessarily fallacious. The reason is that making threats is normal in negotiation dialogue (Walton, 2000). For example, in union management negotiation dialogues, it is common for the union to threaten to go on strike or to go on some sort of job action that might harm the company's interests. 
On the other hand, we can imagine circumstances in which the shift from the one type of dialogue to the other could be evidence of committing an ad baculum fallacy by the party who made a threat. For example, suppose the two robots are engaged in a delicate problem of fixing a short circuit in some of their equipment, and failure to solve the problem could easily result in failure of the mission. Moreover, suppose that there is limited time to solve the problem because several other important jobs also need to be done before liftoff. If the one robot starts making threats and quarreling or negotiating with the other robot at this time, and this interferes with the goals of the deliberation dialogue, and indeed with the goals of the mission as a whole, then the ad baculum argument could certainly be seen as inappropriate in the setting of deliberation dialogue that is underway. For this reason, the argument could be evaluated as an improper or even fallacious use of a threat. However, the robot example is quite simple. That is the nice part of it from the point of view of studying the ad baculum argument. Even though it is an ad baculum argument, for all we know, from the details of the example given, it is a non-fallacious use of this type of argument. However, as indicated, we could think of some hypothetical circumstances in which it would be a fallacious argument.

The problem with the gangster example that prevented us from giving an adequate analysis using the argument diagram in figure 4 that would explain the ad baculum fallacy presumably committed in this case, concerns the gangster's statement that this is a very dangerous neighborhood. The problem was how to fit it into the argument diagram shown in figure 4. In figures 2, 3 and 4 it was shown as a pro-argument supporting the implicit premise stating that if you don't pay protection money, your store will be looted and destroyed. It could also have been repositioned as a premise directly supporting the ultimate conclusion stating that you should pay protection money. However, both of these ways of fitting this statement into the network of argumentation in the case seemed to be inadequate. As indicated in section 5, it seemed that something else was going on. The problem posed is one of how we can build a deeper analysis of the argumentation in the case that goes beyond the structures displayed in figures 2, 3, and 4 .

We can see how the speech acts of warning, advising and threatening each have their individual components by reviewing the argument diagrams of figures 2, 3 and 4 . Figure 2 represents the components of the speech act of warning. The main part of the act of warning is composed of the two statements explicitly made by the gangster, (1) this is a very dangerous neighborhood, 
and (2) the last guy who didn't pay had his store looted and destroyed, right after he failed to pay. Basically, the gangster is warning the storeowner that something bad is about to happen to him, without specifying exactly what the bad event is. However, some indication of what it is like is given in statement (2). Optionally, the conclusion that the store owner should pay the protection money can be included as part of the warning. But the essential part of the warning is the gangster's telling the store owner that something is about to happen that is highly negative from the store owner's point of view.

The components of the speech act of advising can be seen displayed in figure 3 . Here the gangster is not only saying that this is a very dangerous neighborhood, and that the last guy who didn't pay his protection money had his store looted and destroyed. He is also offering a solution to the problem posed by the warning. He is advising the storeowner that if he doesn't pay protection money his store will be looted and destroyed, and in order for the storeowner to avoid these negative consequences, he is advising him to pay protection money. Therefore the argumentation structure represented in figure 3 , taken as a whole, displays the speech act of advising. Figure 3 includes both warning and advising, and shows how the warning speech act is included within the advising speech act as part of it.

Figure 4 displays the speech act of making a threat in the central part of the diagram where the three propositions displayed in the rectangles with dashed borders are lined up vertically with each other. Notice that all the components of the threat are based on implicit assertions attributed to the gangster by implicature. Notice that in figure 4, the warning component is still present in the two propositions shown as explicit premises at the top right. So we can see how warning is connected with threatening by looking at these diagrams. But the problem remains to determine the precise relationship in the example between advising and threatening. The solution to this problem can be provided by mapping the relationships between the speech acts and the arguments, as shown in figure 5.

Figure 5 shows the speech act of warning at the top right of the diagram. Comprising this speech act are the gangster's two explicit statements. The gangster's asserting of these two statements, considered in isolation from the other parts of the argumentation represented in figure 5, can be taken as representing a warning that is part of an advising dialogue. 


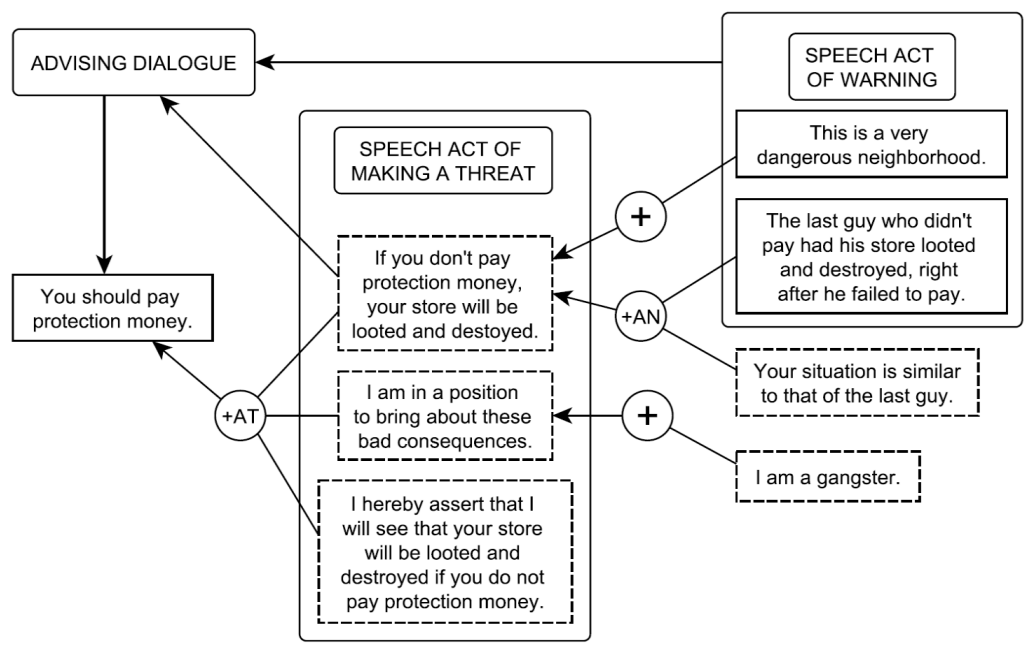

Figure 5: Map of the relationships between the speech acts and the arguments

The two statements that are components of the speech act of warning can be taken as representing an argument in an advising dialogue where the gangster is simply advising the storeowner that he should pay the protection money. The other part of the structure is the speech act of making a threat, represented by the three implicit statements in the big rectangle in the middle of figure 5. This part of the structure has already been shown in figure 5 to make up the implicit premises for an argument from threat that also leads to the conclusion that the store owner should pay the protection money. But now we can see that one of the implicit premises, the statement that if you don't pay protection money, your store will be looted and destroyed, is also part of the advising dialogue that goes along with the other two statements shown in the rectangle representing the speech act of warning.

What this shows is that we can take the argumentation in the case two different ways, and we can see how to do this once we separate the argumentation into its speech act components, the speech act of making a threat and speech act of warning. Then we can see how each of these speech acts contributes both to the advising dialogue and to the ultimate conclusion that the store owner should pay protection money. This way of framing the relationships between the speech act of making a threat and the speech act of warning shows the relationship of both components to the dialogue of advising and also to the argument from threat. It also shows how these components feed into the 
ultimate conclusion. This structure solves the problem of explaining how the ad baculum fallacy works.

\section{Pretending to advise}

Now that we have a speech act of advising, and even more usefully a type of dialogue representing advising discourse, we are in a position to get a deeper analysis of the argumentation in the case. The reason that the gangster says that this is a very dangerous neighborhood is that he is pretending to advise the store owner. He is pretending to advise the store owner on what to do, by warning him about the potential negative consequences of not taking the course of action he advises.

This move can be seen as part of a strategic maneuvering tactic for the gangster to distance himself from having made an explicit threat to the store owner. What the gangster is pretending to do is shown in the argument diagram in figure 1. All the gangster explicitly says is that the store owner should pay protection money because this is a very dangerous neighborhood. This is an argument, the inference link being indicated by the word 'because'. The surface appearance is that the gangster's statement that the last guy who didn't pay had his store looted and destroyed, right after he failed to pay, is merely a statement. But is that really its function in the discourse? No, we all know it was meant as a threat, and will be so taken by the store owner (unless he is very naïve, or is lacking knowledge about his and the gangster's circumstances).

Figure 6 shows the dialectical component. We begin at the left with an advising dialogue in which one party conveys an explicit warning to another party, optionally adding a recommendation on what the other party should do in order to avoid some negative consequences. So far there is no fallacy. There is merely an advising dialogue of the kind illustrated by the two examples from Consumer Reports. The middle box shows what happens when we interpret the text of discourse more deeply and identify the speech act of making a threat. This move constitutes an ad baculum fallacy, as the evidence box at the bottom in the middle indicates.

However, in the gangster example, as shown in figures 4 and 5 , the threat is purely implicit, and so there is an additional dimension in this case. To extract the threat we have to insert missing premises and/or conclusions into the argument by viewing the argument as an enthymeme, an argument that can best be made sense of by inserting implicit premises and conclusions into it.

(C) Douglas Walton. Informal Logic, Vol. 34. No. 3 (2014), pp. 276-310. 


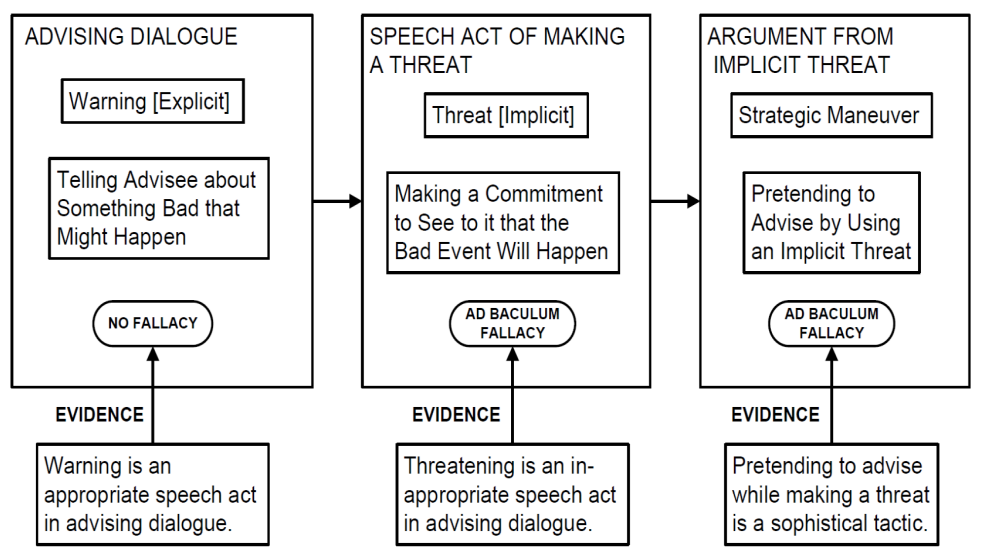

Figure 6: Structure of the ad baculum fallacy

Once the implicit threat has been brought out, we need to take into account the strategic maneuver that the arguer is simply pretending to advise the other party, ostensibly by warning him about some event that will go against his interests, and offering some recommendation on how to avoid these negative consequences. To move to this third stage of the fallacy analysis, we need to identify the argument from threat, even though it is implicit, and recognize that the strategy of using a fallacious ad baculum is one of avoiding responsibility for the threat by leaving a route for plausible deniability. According to this analysis, the ad baculum fallacy, as illustrated by the gangster case, is not simply an error of reasoning. More than that, it is the strategic maneuver, a sophistical tactic, designed not only to strongly motivate the agent to whom it is directed, but also to artfully pretend that the arguer is acting in the helpful capacity of someone who is only giving friendly advice to the respondent. Essentially the gangster trying to immunize himself against future accusations of failure to follow the rules appropriate for this type of dialogue by making a threat instead of arguing.

The juxtaposition of appearance and reality brought out by this analysis of the argumentation in the gangster example is reminiscent of the common definition of a fallacy as an argument that appears to be valid but is not (Hansen, 2002). Appearances can not only be misleading; they can be exploited. Some fallacies are merely errors caused by jumping to a conclusion too quickly, but others are subtle sophistical tactics used to unfairly get the best of a speech partner. 
Now an objection needs to be taken up. The discussion of figure 1 might be criticized by saying that it is irrelevant, because what is at issue is whether $\mathrm{R}_{1}$ 's argument is fallacious, but the figure displays $\mathrm{R}_{2}$ 's argument. The criticism claims that even though $\mathrm{R}_{2}$ 's argument is clearly not fallacious, that says nothing about whether $\mathrm{R}_{1}$ 's argument is fallacious. This criticism misunderstands what figure 1 is designed to show, and leaps to the wrong conclusion. As shown in the discussion under figure 1, the discussion is meant to show that perhaps there is nothing wrong with the argument from $\mathrm{R}_{2}$ 's point of view. The point is that we need to examine whether the argument is fallacious or not from the dialectical point of view by looking at the dialogue protocols of how the argument is put forward by one party, and how it can be responded to by the other party as they take turns making moves in the dialogue. In this instance, as shown by the discussion, the issue depends on how $R_{2}$ is allowed to respond to the argument put forward by $\mathrm{R}_{1}$, if it is important for him to preserve his antenna for future use in the mission, it might make practical sense for him to dig. Looked at from this dialectical perspective, $\mathrm{R}_{1}$ 's argument would not appear to be an instance of the sophistical tactics type of $\mathrm{ad}$ baculum argument that is an attempt to block off the respondent's capabilities for replying. Hence the dialectical analysis of the fallacy proposed in the paper can not only be used to marshal evidence in a given case to show an ad baculum argument is fallacious; it can also be used to show that it has not been used in a fallacious way in the robots example.

\section{Conclusions}

The most general conclusion of this paper is that whether a given ad baculum argument should be properly judged to be fallacious or not is dialectical, meaning that it depends on the type of discourse the argument is supposed to be part of. In a persuasion dialogue or an inquiry dialogue the speech act of making a threat is simply inappropriate. It is easy to rule out threats once one applies a formal model of either of these types of dialogue, because the speech act of making a threat is simply not included in the protocols for the speech acts considered as permitted moves in the dialogue. This phenomenon may explain why ad baculum arguments were considered more or less obviously fallacious for so long in the logic textbooks. It was probably assumed that the context was that of a persuasion dialogue or an inquiry. Also, as shown in the gangster case, an advising dialogue can commonly be joined to deliberation

(C) Douglas Walton. Informal Logic, Vol. 34. No. 3 (2014), pp. 276-310. 
dialogue, and in that main deliberation dialogue, as well as in the embedded advising dialogue, making a threat to the other party should not be included among the allowable speech acts.

The robots example of ad baculum is a case where a direct threat was made. The gangster is an instance of an indirect threat. But in either type of case the basic ten-step procedure set out below can be applied to analyze and evaluate an ad baculum argument.

- The first step is to identify the premises and conclusions in the given argument.

- The second step is to find the inferential links that join these propositions as inferences using an argument diagram.

- The third step is to identify argumentation schemes, such as the one for argument from negative consequences, that might fit any of the argument nodes.

- The fourth step is to fill in any implicit premises or conclusions that are helpful for making sense of the argument.

- The fifth step is to identify speech acts that link the argument to the type of dialogue that represents the communicative context.

- The sixth step is to determine what the initial type of dialogue is supposed to be.

- The seventh step is to inquire further into the details of the case to see if there has been a shift to another type of dialogue.

- The eighth step is to determine whether the speech act, whether it be one of warning, advising or threatening, is an appropriate move in the original type of dialogue.

- The ninth step is to determine how that speech act is being used in the secondary type of dialogue.

- The tenth step is to look for evidence of the commission of a fallacy, for example the use of a sophistical tactic to try to make a threat seem like a warning.

As shown by the two examples treated in the paper, the ten-step procedure is a method for marshaling the textual evidence in a given case, and for using the tools illustrated in the paper to arrive at an evidence-based judgment whether the argument in question should be considered fallacious or not. It is a misconception to think that any particular subset of the requirements formulated in the bullet points have to be satisfied or violated to make an argument fallacious. It would be nice if 
the procedure was that simple, but it is not. The evaluation tools have to be applied to the textual evidence in the given case where it is suspected that an ad baculum fallacy has been committed, and the evidence on both sides has to be considered methodically by going through all ten steps in the evaluation procedure.

This paper has presented a dialectical analysis of the ad baculum fallacy that can help us not only to evaluate ad baculum arguments but also to explain precisely what goes wrong when such an argument is fallacious by pinpointing a group of dialectical failures that can occur. So what has been accomplished in the paper is to provide not only an evaluation procedure for this type of argumentation but also a theory offering an explanation of why it can be justifiable to evaluate certain types of paradigm cases as being instances of the ad baculum fallacy.

As well as being applicable to teaching informal logic skills, this method is applicable to the current technology of building software agents that communicate with each other for various purposes in multiagent systems. For example, autonomous software agents can be used to communicate information about the stock market, to buy and sell stocks, and to negotiate deals. Because they are autonomous, they can go ahead and engage in argumentation in a creative and original way, meaning that they can even commit fallacies, because they are programmed to get the best deal within the allowable moves in their communication protocols. These rules may allow moves like the speech act of making a threat or not. So the potential for an autonomous software agent committing an ad baculum fallacy on the Internet is there.

Another conclusion is the recommendation that a new type of dialogue called advising dialogue should be added to the standard list of seven dialogues recognized so far in the argumentation literature. This new type of dialogue seems in a certain respect subsidiary to the main seven types of dialogue, because it often takes place during an interval in one of the other types of dialogue. It can occur in an inquiry dialogue or an information-seeking dialogue, but as its three stages have been framed in this paper, the opening stage posits the need to solve a problem or make a decision, characteristic features of a deliberation dialogue.

An interesting subject for further study would be the relationship of argument from expert opinion, which is a wellknown argumentation scheme and set of critical questions, to advising dialogue. So far in the literature, the argumentation scheme for argument from expert opinion has been mainly

(C) Douglas Walton. Informal Logic, Vol. 34. No. 3 (2014), pp. 276-310. 
deployed and studied in a context of persuasion dialogue. But now it appears that argument from expert opinion and its relationship to critical questioning may be a more complex matter than we previously thought. We now need to recognize that evaluation of instances of expert opinion advice needs to be carried out not merely by considering one simple argument move or speech act, but by examining a connected sequence of moves that represents a special type of discourse in its own right. Study of advising discourse is a significant topic for further investigation of the ad baculum fallacy, as well as other problems in argumentation studies.

A problem posed by this paper, a highly significant and central one for argumentation studies, is that of enthymemes, the problem of filling in implicit premises and conclusions in an argument diagram. The findings of this paper suggest that one of the most important means of working toward a systematic method for dealing with this problem is to use speech acts within dialectical structures where the speech acts are used to define the permissible moves in a dialogue.

Acknowledgements: Work in this paper was supported by Social Sciences and Humanities Research Council of Canada Insight Grant 435-2012-0104: the Carneades Argumentation System.

\section{References}

Brinton, A. (1992). The Ad Baculum Re-Clothed, Informal Logic, 14 (2 \& 3), 85-92.

Budzynska, K. and Witek, M. (2014). Non-Inferential Aspects of Ad Hominem and Ad Baculum, Argumentation, to appear.

Copi, I.M. and Cohen, C. (1990). Introduction to Logic. New York: Macmillan.

Grice, H. P. (1975). Logic and Conversation, Syntax and Semantics, vol. 3, ed. P. Cole and J. L. Morgan. New York: Academic Press, 1975, 43-58.

Gordon, T. F. (2010). The Carneades Argumentation Support System, Dialectics, Dialogue and Argumentation, ed. C. Reed and C. W. Tindale. London: College Publications.

Hansen, H. V. (2002). The Straw Thing of Fallacy Theory: The Standard Definition of Fallacy, Argumentation, 16, 133-155.

Johnson, R. H. (1996). The Need for a Dialectical Tier in Arguments, FAPR, volume 1085 of Lecture Notes in Computer Science, 349-360. Berlin: Springer. 
Kauffeld, F. J. (2000). Arguments on the Dialectical Tier as Structured by Proposing and Advising, Argumentation at the Century's Turn: OSSA 1999 Proceedings, CD, 1-34.

Kielkopf, C. (1984). Relevant Appeals to Force, Pity \& Popular Pieties, Informal Logic, 2(2), 2-5.

Kraus, S., Sycara, K. and Evenchik, A. (1998). Reaching Agreements through Argumentation: A Logical Model and Implementation, Artificial Intelligence, 103, 1-60

Levinson, S. (1983). Pragmatics, Cambridge: Cambridge University Press.

F. Macagno and D. Walton (2013). Implicatures as Forms of Argument, Perspectives on Pragmatics and Philosophy, ed. A. Capone et al. Berlin: Springer, 203-224.

McBurney, P. and Parsons, S. (2002). Dialogue Games in MultiAgent Systems, Informal Logic, 22(3), 257-274.

Reed, C. (2011). Implicit Speech Acts Are Ubiquitous. Why? They Join the Dots, Zenker, F. (ed.). Argument Cultures: Proceedings of the 8th International Conference of the Ontario 2011. Windsor, ON (CD ROM), 1-15.

Parsons, S. and Jennings N. (1997). Negotiation through Argumentation: A Preliminary Report. Proceedings of the Second International Conference on Multi-Agent Systems, ed. M. Tokoro. Menlo Park, California: AAAI Press, 267-274.

Russell, S. J. and Norvig, P. (1995). Artificial Intelligence: A Modern Approach. Upper Saddle River: Prentice Hall.

Scheuer, O., Loll, F., Pinkwart, N. and McLaren, B. M. (2010). Computer-supported Argumentation: A Review of the State of the Art, Computer-Supported Collaborative Learning, 5 (1), 43-102.

Searle, J. (1969). Speech Acts. Cambridge: Cambridge University Press.

Tindale, C. W. (2007). Fallacies and Argument Appraisal. Cambridge: Cambridge University Press.

Van de Vate, D. (1975). The Appeal to Force, Philosophy \& Rhetoric, 81 (1975), 43-60.

Van Eemeren, F. H. (2010). Strategic Maneuvering in Argumentative Discourse. Amsterdam: Benjamins.

Walton, D. (1996). Argumentation Schemes. Mahwah: Erlbaum. Walton, D. (1995). A Pragmatic Theory of Fallacy, The University of Alabama Press, Tuscaloosa and London.

Walton, D. (2000). Scare Tactics, Kluwer Academic Publishers, Dordrecht.

Walton, D. and Krabbe, E. C. W. (1995). Commitment in Dialogue. Albany: State University of New York Press. 
Walton, D., Reed, C. and Macagno, F. (2008). Argumentation Schemes, Cambridge: Cambridge University Press.

Woods, J. (1987). Ad Baculum, Self-interest and Pascal's Wager, Argumentation: Across the Lines of Discipline, ed. F. H. van Eemeren et al. Dordrecht: Foris, 343-349.

Woods, J., and Walton, D. (1976). Ad Baculum, Grazer Philosophische Studien, 2, 133-140.

Wreen, M. (1988). Admit No Force But Argument, Informal Logic, 10 (2), 89-95. 